\title{
Os enunciados científicos no ensino médio e as práticas para a formação do sujeito-químico
}

\section{The scientific statements in secondary education and the practice to the formation of the chemical-subject}

\author{
Angélica Cristina Rivelini-Silva ${ }^{1}$, Moisés Alves de Oliveira ${ }^{2}$
}

\begin{abstract}
Resumo
O trabalho procura problematizar os processos de naturalização de determinados enunciados químicos e deslocar o olhar, dos saberes químicos, para um conjunto de práticas que regulam a forma como os alunos do Ensino Médio produzem conhecimento químico, para então, entender como os saberes químicos são produzidos por determinados discursos. Como estratégias, a metodologia foi parte constitutiva da representação investigativa e foi composta no próprio caminhar da pesquisa, as técnicas etnográficas foram utilizadas para a coleta e registro de dados. As análises desses dados foram construídas com base na análise do discurso foucaultiano, que permitiu conhecer os processos pelos quais os alunos apropriam os enunciados químicos e os colocam em funcionamento. Os discursos vão incorporando os termos próprios da química, que passam a funcionar em uma nova rede discursiva.
\end{abstract}

Palavras-chaves: Enunciado. Prática discursiva. Naturalização. Ensino de Ciências.

\begin{abstract}
This research aims to question the naturalization process of certain chemical statements and shifted his gaze, of the chemical knowledge, to a set of practices that regulate how high school students produce chemical knowledge to understand how chemical knowledge is produced by certain addresses. As strategies, the methodology was a constituent part of the investigative representation and it was made on the same path of the research, the ethnographic techniques were used to collect and record data. The analyzes of these data were based on the analysis of Foucault's discourse, which allowed us to know the processes by which students appropriated chemical statements and put them into operation. The speeches are incorporating their own chemical terms that will function in a new discursive network.
\end{abstract}

Keywords: Discursive Practice. Naturalization. Science Education.

${ }^{1}$ Doutora em Ensino de Ciências e Educação Matemática pela UEL. Professora Adjunta no Ensino de Química na UTFPR

${ }^{2}$ Doutor em Educação Básica pela Universidade do Vale do Rio dos Sinos. Professor Associado Universidade Estadual de Londrina 


\section{Introdução}

Apresentamos os resultados de uma pesquisa, de mestrado, que buscou entender como os enunciados, que circulam em aulas de Química, produzem determinadas subjetividades ${ }^{3}$. Apresentamos as análises dos discursos de aulas, de Química Analítica, ao estudar como as práticas discursivas promovem os discursos, próprios, da Química e como eles passam a funcionar no processo de formação dos alunos/sujeitos.

Sujeitos que buscam uma formação técnica como alternativa à universitária, especialmente pelo fato do curso ter duração de dois anos, conferindo aos formandos habilitações para o trabalho em laboratórios. Apesar da educação de nível Técnico no estado do Paraná, ser regulamentada pelas "Diretrizes da Educação Profissional: fundamentos políticos e pedagógicos" (PARANÁ, 2006). Que afirmam que a

[...] política de retomada da Educação Profissional no Estado, a partir de 2003, assume-se uma concepção que rompe com a dimensão que a articula diretamente ao mercado de trabalho e à empregabilidade e laboralidade. Assume-se, também, o compromisso com a formação humana dos alunos, a qual requer a apreensão dos conhecimentos científicos, tecnológicos e histórico sociais pela via escolarizada (PARANÁ, 2006, p. 20, grifo nosso).

Pudemos observar a busca pela formação do profissional-químico, mesmo que as diretrizes assumam a ruptura da formação ligada ao treino para o mercado de trabalho, ou como preparação exclusiva a este fim, o Curso Técnico Profissionalizante em Química, modalidade Pósmédio ${ }^{4}$, arrasta uma marca de formação para o trabalho em laboratório, situação observada na relação estabelecida com a necessidade de utilizar o laboratório e ensinar técnicas corretas de manuseio de vidrarias e reagentes.
As disciplinas do currículo, são selecionadas para proporcionarem aos alunos conceitos e técnicas específicos ao profissional da Química. Com esse cenário, propomos estudar os efeitos das apropriações dos enunciados científicos/químicos. Tendo como referencial teórico e metodológico a obra do filósofo Michel Foucault, especialmente o conceito de discurso, que será discutido com mais detalhes ao longo do trabalho.

Se nossas análises visam as práticas discursivas, entendemos que essas são produzidas no interior de determinados discursos e estão sempre envolvidas em relações de poder, "relações que procuram impor determinados significados (e não outros quaisquer)" (VEIGA-NETO, 2000, p. 10). Ao identificar as articulações e negociações presentes nas relações, nas aulas, e compreender o saber nela produzido, procuramos nas práticas discursivas - nos enunciados químicos - um sistema de normas e princípios que acabam por constituírem os objetos e sujeitos. Nesse sentido, pretendemos entender como as práticas se articulam na produção de uma determinada verdade, em uma forma de ser.

\section{Por uma prática discursiva}

O pensamento de Foucault, desde o início, apresenta críticas a ideia de sujeitos a-históricos, esse pensamento motiva nossa pesquisa. Justamente no desafio de fazer uma análise que remeta às práticas constitutivas do sujeito-químico, entremeado a história de seu processo de subjetivação enquanto aluno do curso. Assim, olhamos para o sujeito como constituído nas práticas discursivas, em bases que the são exteriores e segundo uma modalidade específica do conhecimento científico (REVEL, 2005).

Para compreendemos como as práticas discursivas produzem seus efeitos, precisamos

${ }^{3}$ Subjetividade para pensar o sujeito como historicamente constituído, não acabado e em constante relação. O conceito de subjetividade como se constituindo em uma série de subjetividades diferentes, que "jamais terão fim e não nos colocam jamais diante de alguma coisa que seria o homem”, dado como pronto e acabado (REVEL, 2005, p. 85).

4 Voltado para pessoas que já completaram o ensino médio e buscam uma qualificação técnica. 
primeiramente entender os conceitos de discurso e o enunciado. A noção foucaultiana de discurso não está apoiada no significado das palavras, mas em uma maneira de referir-se às coisas, às pessoas ou à realidade. A análise fica centrada "nas práticas que formam", que constituem "os objetos" sobre os quais falam; assim, os discursos "instituem, os objetos dos quais falam" (REVEL, 2005, p. 157). Foucault demonstrou em seus trabalhos que o discurso é produtivo e acaba por produzir subjetividades, instituições, efeitos de poder e de verdade. Para esta pesquisa, ele permite produzir formas de ver, de ser, de agir e de viver.

Larrosa (2010, p. 66), ao trabalhar a concepção foucaultiana de discurso, o "define como mecanismo autônomo [...], funcionando no interior de um dispositivo". Ao chamar a atenção para tais discursos, tem-se em vista a autonomia destes e a "instrução metodológica de analisá-lo em si mesmo, na medida em que tem suas próprias regras" (LARROSA, 2010, p. 66). O discurso teria, então, seu próprio modo de existência, sua coerência, suas regras e suas próprias determinações.

Foucault, no livro Arqueologia do Saber, nos coloca que "analisar a positividade é mostrar segundo que regras uma prática discursiva pode formar grupos de objetos, conjuntos de enunciados, jogos de conceitos, séries de escolhas teóricas" (FOUCAULT, 2012, p. 205). E esta característica produtiva dos discursos é trabalhada por Foucault como "práticas que formam sistematicamente os objetos de que falam" (FOUCAULT, 2012, p. 56). Mas o autor nos lembra de que os discursos são feitos de signos, no entanto, "o que fazem é mais que utilizar estes signos para designar coisas. É esse mais que os tornam irredutíveis à língua e ao ato da fala. É esse 'mais' que é preciso fazer aparecer, que é preciso descrever" (FOUCAULT, 2012, p. 56). O discurso, entre as diversas definições dadas por Foucault, pode ser entendido como "um conjunto de enunciados que se apoiem na mesma formação discursiva" (FOUCAULT, 2012, p. 135).
O enunciado deve ser tomado como histórico isso quer dizer que ele deve estar relacionado a suas regras de formação, ele é (re)inventado a cada época/uso. Por exemplo, a Química é constituída por enunciados formulados em diversos momentos da história. Mas, as relações que ele estabelece e os novos sentidos que ganha, produzem novamente a química. Se procurarmos em outras épocas, encontraríamos uma série de outras formulações de enunciados que nada se relacionam com a química de hoje.

O enunciado sempre tem correlação, ele nunca aparece isolado, "trata-se de compreender o enunciado na estranheza e singularidade de sua situação; de determinar as condições de sua existência, [...] de estabelecer suas correlações com outros enunciados" (FOUCAULT, 2012, p. 31). Os enunciados estão sempre apoiados em um grupo de signos, mas o que realmente deve ser pensado é o fato dele se caracterizar por quatro elementos fundamentais: um referente; um sujeito; um campo associado; e uma materialidade específica.

Para as analises que faremos das práticas discursivas, buscamos identificar esses quatro elementos para dar conta dessa sua especificidade. Pois, o enunciado irrompe num certo tempo, num certo lugar e em certa situação "o que lhe permite aparecer, justaporse a outros objetos, situar-se em relação a eles, definir sua diferença, sua irredutibilidade e, eventualmente, sua heterogeneidade; enfim, ser colocado em um campo de exterioridade" (FOUCAULT, 2012, p. 51).

E, justamente tendo o enunciado científico em foco, faremos uma leitura das práticas discursivas, inspirada no entendimento de discurso que nos deixou Foucault. Por esta perspectiva, tomamos aulas de Química Analítica por aquilo que dizem, por suas práticas. A seguir, apresentamos os caminhos e as escolas tomadas para que a pesquisa aconteça. 


\section{Metodologia}

Apresentamos a pesquisa realizada no Curso Técnico em Química, oferecido por um Colégio Estadual na Cidade de Apucarana, Paraná. Local em que acompanhamos aulas teóricas e práticas da disciplina de Química Analítica, interagindo com a professora, os alunos, coordenadores do curso, as diretoras e outros professores; buscando possibilidades de entender e continuar a questionar como as aulas se tornam espaços para produção, que permitem, em suas singularidades, a negociação e a apropriação dos enunciados químicos. E ainda, ao estabelecer relação com o mercado de trabalho, leva ao processo de subjetivação do sujeitoquímico, inserido em um regime discursivo.

Utilizamos a metáfora larrosiana da 'viagem' para relatamos o processo de pesquisa e inserção no campo. Utilizar esta metáfora é um recurso já usado em outros estudos na área das ciências sociais e humanas (LOURO, 2004; SANTOS, 2005). Intencionamos com a viagem empreendida reconhecer e problematizar um determinado contexto cultural vivido por alunos e professores em seus lócus. E a partir dele, problematizar questões tomadas como familiares ou naturais para o ambiente escolar.

Desta forma, falamos sobre "como" e "onde" esta pesquisa foi realizada e seus (des)caminhos, entendendo o método como parte constitutiva da representação investigativa, que se constitui no próprio andar da pesquisa. Adotamos, assim, a metáfora da viagem para, pouco a pouco, relatar as descobertas do caminho. Esse aspecto se dá quando o processo de ida a campo evidencia algumas referências turísticas presentes durante as visitas, que mostram o processo de excursão do pesquisador e sua inserção no lugar, pressupondo um projeto de condução, roteiro e registros. Nas palavras de Santos (2005):

São, enfim, muitas as possibilidades de ter estado lá. Possibilidades essas que variam em intensidade, em risco, em capacidade de se "miscigenar", de se misturar com hábitos, valores, crenças, modos de ver, enfim, de tornar-se mais um(a) daquele lugar (de ser menos estrangeiro(a)). Efetivamente, esta é uma das tentativas do(a) etnógrafo(a). É também por esta experiência que ele(a) é autorizado(a) a falar (SANTOS, 2005, p. 11).

São evidentes as diferenças entre um pesquisador e um turista. Como os objetivos, modos de ver e de sentir muito distintos, mas que se aproximam, porque ambos pressupõem uma viagem, um deslocamento e um desejo de conhecer estilos, modos de vida e paisagens diferentes (SANTOS, 2005). Para esta pesquisa, algo parecido aconteceu. Foi necessário estar lá, participar dos planejamentos, das reuniões, de aulas, interagir com as pessoas, lanchar com professores e alunos, tirar fotos, gravar conversas, enfim, além de observar, participar, um pouco, do que configura o dia a dia da escola e dos alunos do curso técnico; para depois, retornar e escrever aqui:

\begin{abstract}
A escrita e a descrição buscam, então, recuperar, (re) constituir o lá vivido[...]. Os objetos trazidos, as fotos, as anotações do diário de campo/de viagem funcionam, nesta (re)constituição, como matéria para compor/ilustrar a história que se conta - eles dão autenticidade à narrativa do(a) contador(a). Tenta-se com eles, e com o artifício da palavra, (re)compor uma "realidade" vivida e assim trazê-la àqueles(as) que aqui ficaram (SANTOS, 2005, p. 12-13).
\end{abstract}

O que fazemos, "trata-se, sobretudo, de uma remontagem (de um re-contar a viagem) que pretende problematizar a sua própria constituição enquanto metodologia de trabalho, expondo suas colagens, fraturas" (SANTOS, 2005, p. 20). Sendo assim, o escrito, descrito e analisado aqui, fazem parte de um modo de olhar para a escola, que foi se configurando durante a viagem/pesquisa. Concordando com Veiga-Neto (1996, p. 15), "são as nossas práticas e os olhares que colocamos sobre as coisas que as criam como elementos pensáveis, que as fazem sujeitos e objetos de enunciação, ou as certezas nas quais confiar, ou os problemas a resolver".

Para que a viagem/pesquisa começasse pedimos autorização à diretora do Colégio, na sequência, com a professora, os coordenadores e alunos. Todos os envolvidos demonstraram interesse em participar 
da pesquisa. Apresentamos a eles um Termo de Consentimento Livre e Esclarecido (TCLE), antes de iniciar as observações, no qual explicitamos os objetivos da pesquisa, o acompanhamento das atividades por eles desenvolvidas e o registro de imagens e som durante as atividades. Como consta no termo, a identidade dos participantes foi preservada, adotando-se nomes fictícios para os fins do trabalho.

A pesquisa de campo durou aproximadamente quatorze meses, nesse período mantivemos um diário de campo, que se tornou o registro das vivencias, lembranças e dados. Além do diário, realizamos os registros de áudio e imagens, sempre que a aula permitia. Para registrar a rotina, circulamos por uma variedade de espaços e de trabalhos que compunham as atividades da turma, como: aulas práticas e teóricas, horários de intervalos, visitas a empresas e estágios supervisionados.

A turma que acompanhamos era denominada $1^{\circ}$ Ano A, tinha vinte e dois alunos matriculados. Era composta por alunos de dezoito a cinquenta e cinco anos, alguns já trabalhavam em laboratórios, outros trabalhavam no comércio, muitos vieram direto do Ensino Médio para o técnico. A disciplina que acompanhamos foi a de Química Analítica, ministrada pela professora Flávia, ela é licenciada em Química e trabalhava durante o dia em um laboratório de controle de qualidade e a noite no curso Técnico. A seguir, uma tabela com o nome, idade e profissão dos alunos que terão suas falas apresentadas nesse texto.

Tabela 1 - Alunos participantes da pesquisa

\begin{tabular}{|l|l|l|}
\hline \multicolumn{1}{|c|}{ Nome Fictício } & \multicolumn{1}{c|}{ Idade } & \multicolumn{1}{c|}{ Profissão } \\
\hline Valdir & 55 & Auxiliar Laboratório \\
\hline Rosângela & 35 & Auxiliar Laboratório \\
\hline Thomaz & 50 & Auxiliar Laboratório \\
\hline Nayara & 22 & Estudante \\
\hline Ney & 26 & Vendedor \\
\hline Ana & 27 & Estudante \\
\hline
\end{tabular}

Fonte: Autores.

Ao olhar as falas destes alunos, analisamos o funcionamento da disciplina de Química Analítica, focamos as práticas discursivas, ao se caracterizarem como recortes do campo, por definir uma perspectiva legítima para o sujeito, pela demarcação de "normas para elaboração dos conceitos e das teorias. Cada uma delas supõe, portanto, um jogo de prescrições que regem exclusões e escolhas" (FOUCAULT, 2013, p. 125).

É no processo de exclusão e escolhas que localizamos nossa pesquisa, ao procurar entender como essas práticas produzem o sujeito-químico. Pois, no processo de exclusão e escolhas a eficácia dos discursos ganha força em práticas, "esses princípios não remetem a um sujeito do conhecimento [...] eles designam melhor uma vontade de saber' (FOUCAULT, 2013, p. 7). Para a leitura dos dados de campo, focaremos as 'práticas de formar o sujeitoquímico', apresentadas em episódios de aulas a seguir.

\section{Resultados e Discussões}

Uma noite de aula, a professora entra na sala, cumprimenta os alunos e vai pedindo silêncio e dispara: "Turma, hoje vamos continuar a preparação de soluções, vamos abrir o caderno que vou passar uma parte da teoria no quadro". A "rotina escolar" nos termos de Veiga-Neto, (2001, p. 113) é “um lócus em que se dá de forma mais coesa, mais profunda e mais duradoura a conexão entre saber e poder", a professora entoa o ritmo que é repetido ano após anos nas escolas, a necessidade de despejar uma vasta quantidade informações a fim de seguir 
um planejamento escolar. Os alunos em resposta à suas orientações abrem os cadernos e se colocam apostos a iniciar a cópia, não, isso não significa passividade, mas a reafirmação da importância em pensar a escola como um mecanismo imerso em relações, negociações e contestações. Na sequência, a professora fez uma pequena apresentação no quadro, sobre preparo de soluções e volta-se para os alunos pedindo para que terminem a cópia. Ela iria explicar. Enquanto aguardava, fez a chamada, voltou à frente da sala dizendo:

Professora Flávia: "Gente! Vamos prestar atenção aqui. Vamos aprender como calcular a concentração de soluções, prestem atenção que isso vai ser muito importante para vocês no laboratório. Antes disso, o que é mesmo coeficiente de solubilidade?"

Aluno Valdir: "Professora, não é a quantidade máxima de uma coisa que pode ser dissolvida na outra, na água?"

A professora balançou a cabeça para um lado e para o outro, pensou um pouco e então falou:

Professora Flávia: "É mais ou menos isso! Seria melhor dizer, é a quantidade necessária de uma substância para saturar um solvente”.

Aluno Valdir: "Isso que eu quis dizer!" (Diário de campo, 2010).

A resposta do aluno causou alguns risos na turma, uma conversa paralela e ainda comentários sobre o conceito de 'solubilidade'. Ao intervir na resposta do aluno, a professora buscou ajustar sua fala, que seria o termo 'correto' na linguagem química. Pensando em uma perspectiva foucaultiana de processo de apropriação do discurso, que se define quando a professora, utilizando de diferentes estratégias - a fala, o quadro negro e a confirmação com outros alunos - vai moldando os discursos em um campo próprio da química. Neste processo de apropriação discursiva, os enunciados ganham sentido na medida em que são "institucionalizados, recebidos, empregados, reutilizados, combinados entre si” (FOUCAULT, 2012, p. 131).

A sala de aula se transforma em lócus férteis, para que sujeitos atravessados por seus interesses pessoais e institucionais negociem e articulem a apropriação dos enunciados químicos.

A professora utiliza uma apostila como material validador dos discursos químicos e confere a este, um referencial para consultas ao dizer: "Na apostila que eu passei para vocês, tem uma tabelinha com o coeficiente de solubilidade em água, dos sais que a gente mais usa. Quando precisar, podem consultar lá". De certa forma, a apostila distribuída pela professora marcava e direcionava o que era estudado, para uma orientação e uma experiência "legítima" do que constitui a química. Pensando assim, a apostila atuava como um marcador ao legitimar a fala da professora, ao mesmo tempo em que direcionava o que estudar na institucionalização dos enunciados químicos.

Enquanto ela falava, grande parte dos alunos folheou a apostila em busca da tabela. O aluno Manuel perguntou em qual página, pois não estava encontrando. A professora respondeu, ele então fez uma dobra na página, uma "marca", um referencial que deveria ser consultado e que permitia um direcionamento para os conteúdos da química.

Nessa direção, as aulas tornam-se enquadramento dos saberes e dos sujeitos que, ao fixar determinadas normas, ordena, controla e sistematiza a circulação de conceitos, teorias e procedimentos, estabelecendo um sistema de significação no qual os enunciados químicos podem ser vistos e compreendidos pelos alunos. E para garantir que os enunciados químicos sejam compreendidos dentro deste "quadro disciplinar" (FOUCAULT, 2012, p. 127), a professora utilizase de regras, técnicas e estratégias para 'ajustar' o olhar - dos alunos.

Operando em uma rede discursiva, rotineira em aulas, os enunciados só adquirem significado enquanto objeto da química após o que Foucault (2012) chama de processo de apropriação do discurso, tornando-se um fato bem instituído quando posicionados num sistema de significação regido por 
discursos e práticas desse campo de saberes. Está prática permite significar um enunciado, podemos chamá-la de:

[...] processos de apropriação do discurso: pois, em nossas sociedades (e em muitas outras, sem dúvida), a propriedade do discurso - entendida ao mesmo tempo como direito de falar, competência para compreender, acesso lícito e imediato ao corpus dos enunciados já formulados, capacidade, enfim, de investir esse discurso em decisões, instituições ou práticas está reservada de fato (às vezes mesmo, de modo regulamentar) a um grupo determinado de indivíduos [...] (FOUCAULT, 2012, p. 75).

No exceto acima, nos coloca que para termos o "direito de falar" e "competência para compreender" em um determinado campo discursivo precisamos ser nele 'iniciados' precisamos aprender ou melhor (re)significar. Assim, continuando a aula,

Professora Flávia: "Bom, vamos imaginar uma solução saturada de água e cloreto de sódio. Se a gente olhar na tabela vai ver que a concentração desta solução é de 357g/L. Certo? Acharam? Se eu pipetar uma alíquota de $10 \mathrm{ml}$ desta solução e colocar em um balão de $100 \mathrm{ml}$ e elevar o volume, qual será a concentração desta nova solução?

Aluna Nayara: "Professora, o que é aliq....?"

Professora Flávia: "Aliquota?"

Aluna Nayara: "Isso! Alíquota, o que é isso?".

(Diário de Campo, 2010).

Para responder à aluna, a professora devolve a pergunta à sala, pedindo que os colegas ajudem a Nayara. Passado um momento de silêncio, ela diz:

Professora Flávia: "Valdir, Rosangela, pessoal que já trabalha no laboratório. O que é uma aliquota?”.

Aluno Valdir: “Ah! Professora, a gente fala alíquota quando é pra pegar um pouco de uma amostra, a parte que vou analisar".

Aluno Ney: "Então, é uma parte da solução?"

Aluna Nayara: "a alíquota é a amostra da amostra?"

Professora Flávia: "Isso! Podemos dizer que sim! É uma parte determinada da amostra que estamos trabalhando ou analisando, como falou o Valdir" (Diário de Campo, 2010).
Pensando neste momento de aula, um processo de apropriação se pôs a funcionar, e nesta singularidade os enunciados passam por (re) significações, "a alíquota é a amostra da amostra". O Valdir comenta, "eu nunca tinha pensado assim", "é verdade eu tiro uma amostra da amostra que vou analisar"; concorda a Rosângela, "é um jeito legal de explicar".

Analisar os enunciados que circulam no curso pedem um olhar minucioso, dedicado às pequenas relações, para isso nós apoiamos no trabalho desenvolvido por Fischer (2001), ao colocar que os enunciados se caracterizam por quatro condições - um referencial, um sujeito, um campo e uma materialidade; olhemos para o enunciado 'pipetar uma alíquota'. Podemos observar que ele se constitui de signos - palavras, entretanto o que devemos olhar, segundo Foucault (2013a), é para a sua condição de enunciado, o que ele requer para se realizar como tal.

Um referencial, não como um fato, objeto específico ou estado, mas como a diferenciação, relação com situações que identificamos. 'Pipetar uma alíquota' - pipetar relacionado ao laboratório e as atividades analíticas pertinentes ao uso de pipetas. A palavra alíquota está mais próxima do campo discursivo matemático, entretanto, a relação com fragmentar ou dividir foi levantada. Juntas, 'Pipetar uma alíquota', ganha contornos próprios na materialidade do grupo.

Se buscarmos o(s) sujeito(s) associado(s) a esse enunciado, teremos aquele(s) que confirmam o que se diz; o profissional Químico, aquele que no laboratório, analisa e quantifica as amostras, ocupa o papel de sujeito detentor da prática, da técnica e do discurso. Temos também os professores de química, que reafirmam e se reconhecem nesse discurso, diversas vezes proferidas em aulas.

Os enunciados pressupõem sujeitos que lhe coloquem em funcionamento, mas também um campo - discursivo - associado. Na relação e 
associação a outros enunciados do mesmo discurso, encontrados no livros e apostilas do curso, na comunidade científica, nas aulas de Química Analítica ou na fala do Valdir: "Professora, a gente fala alíquota quando é pra pegar um pouco de uma amostra, a parte que vou analisar", outros enunciados se associam para que, no caso, 'alíquota' passe a funcionar.

Ao funcionar em um campo discursivo, o enunciado adquire materialidade, surge de forma mais concreta e dispensa explicações. A fala da professora ao ajustar a condição do que seria a 'alíquota' e o reforço dos colegas auxiliares de laboratório, dão a materialidade necessária. Os alunos do Curso Técnico, em busca da formação do sujeito-químico, apropriam-se desses enunciados e lhes conferem materialidade ao colocá-los em funcionamento em seu cotidiano.

A teoria do discurso está intimamente ligada à questão da constituição do sujeito. Se a química é significada, os indivíduos envolvidos no processo de significação também o são e isto resulta em uma consideração fundamental: os sujeitos sociais não são causas, não são a origem do discurso, mas são efeitos discursivos (FISCHER, 2001). Descrever uma formulação enquanto enunciado não consiste em analisar as relações entre o autor e o que ele disse (ou quis dizer, ou disse sem querer); mas em determinar qual é a posição que pode e deve ocupar todo indivíduo para ser seu sujeito (FOUCAULT, 2012, p. 109).

Embora um discurso científico, institucionalizado - 'alíquota, amostra, analisar', parece surgir das negociações no próprio grupo, são as experiências, as relações com seus pares que permitem, então, uma ressignificação contingente e local. De resto, ocorre um apagamento das origens e a reinvenção, mais próxima aos interesses e possibilidades do grupo. Essa argumentação dos alunos gera uma irrupção que permite a significação do enunciado alíquota, ele ganha contornos próprios para o grupo.

\section{(In)Conclusão}

Para terminar, retomemos à metáfora da viagem, ao comparar este trabalho com as recordações, sentimentos e desejos que trazemos. Muitas são as possibilidades, cada viagem é única, e essa singularidade se deve às nossas escolhas e aos acontecimentos que vão direcionando nossos olhares e caminhos. Ao fim desta viagem/pesquisa, tenhamos a consciência que não visitamos todos os lugares possíveis e que poderia retornar outras vezes e ver muito mais e de maneiras diferentes.

Mas a questão central desta pesquisa/viagem foi percorrer os processos que dão materialidade aos Enunciados em aulas de Química Analítica e entender as regras daquilo que é dito e como eles atuam para produzirem o profissional Técnico em Química. Essas questões foram olhadas a partir de um referencial teórico que não procurou explicar, comprovar ou resolver os problemas, mas sim fazer estranhar, problematizar aspectos que não haviam sido pensados desta forma. Ao falar sobre a (re)significação e apropriação dos enunciados químicos, o direito de falar e as forma de visibilidade descrevemos e analisamos esse tema por uma das muitas maneiras de abordá-lo.

Iniciamos o estudo em um local considerado conhecido, mas as escolhas teóricas que fizemos, durante todo o processo, implicaram o abandono de uma visão naturalizada da prática escolar, isso provocou desestabilizações e dúvidas.

Agora, ao chegar aqui, destacamos a importância de entender a ciência como uma prática cultural, com suas especificidades que acabam legitimando o conhecimento científico. E a escola como espaço de relações dos saberes e dos sujeitos, visto que ao estabelecer normas ela ordena, controla e sistematiza as teorias e procedimentos. Dessa maneira, estabelece um sistema de significação, no qual os enunciados químicos ganhavam sentido nas práticas cotidianas. 


\section{Referências}

FISCHER, R. M. B. Foucault e a análise do discurso em educação. Cadernos de Pesquisa, São Paulo, n. 114, p. 197-223, nov. 2001.

FOUCAULT, M. A arqueologia do saber. 8. ed. Tradução de Luiz Felipe Baeta Neves. Rio de Janeiro: Forense, 2012.

FOUCAULT, M. A ordem do discurso: aula inaugural no Collège de France, pronunciada em 2 de dezembro de 1970. Tradução de Laura F. A. Sampaio. Campinas: Loyola, 1998.

FOUCAULT, M. As palavras e as coisas: uma arqueologia das ciências humanas. 8. ed. Tradução de Salma Tannus Muchail. São Paulo: M. Fontes, 2000.

FOUCAULT, M. Micrifísica do poder. Rio de Janeiro: Graal, 2013.

FOUCAULT, M. Vigiar e punir: história de violência nas prisões. 33. ed. Tradução de Raquel Ramalhete. Petrópolis: Vozes, 2013a.

LARROSA. Tecnologias do Eu e Educação. In: SILVA, T. T. Sujeito da Educação: estudos foucaultianos. Petrópolis: Vozes, 2010. p. 35-86.

LOURO, G.L. Um corpo estranho: ensaios sobre a sexualidade e teoria queer. Belo Horizonte: Autêntica, 2004.

PARANÁ. Secretaria de Estado da Educação. Diretrizes da educação profissional: fundamentos políticos pedagógicos. Curitiba: SEED, 2006. Disponivel: <http://www.diaadiaeducacao.pr.gov. br/>. Acesso em: 10 jun. 2016.

REVEL, J. Michel Foucault: conceitos essenciais. São Carlos: Claraluz, 2005.

SANTOS, L.H.S. Sobre o etnógrafo-turista e seus modos de ser. In: Caminhos investigativosIII: riscos e possibilidades de pesquisar nas fronteiras, by Marisa Vorraber Costa e Maria Isabel Edelweiss Bujes, p.9-22 Rio de Janeiro: DP\&A, 2005.
VEIGA-NETO, A. A ordem das disciplinas. 1996. 336 f. Tese (Doutorado em Educação) - Universidade Federal do Rio Grande do Sul, Porto Alegre, 1996.

VEIGA-NETO, A. Incluir para excluir. In: LARROSA, J.; SKLIAR, C. Habitantes de Babel: políticas e poéticas da diferença. Tradução de Samíramis Gorini da Veiga. Belo Horizonte: Autêntica, 2001.

VEIGA-NETO, A. Michel Foucault e os estudos culturais. In: COSTA, M. V. Estudos culturais em educação. Porto Alegre: Ed. UFRS, 2000. p. 37-69. 
